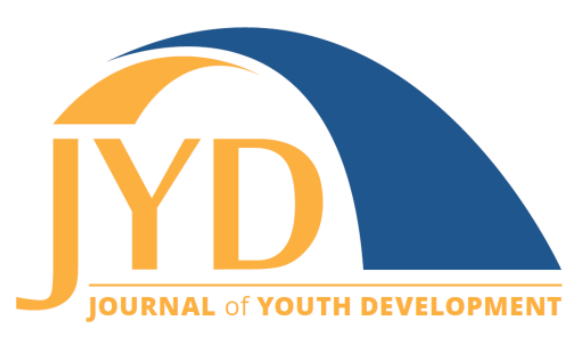

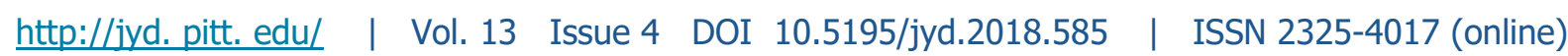

\title{
Feasibility and Fit of a Mental Health Promotion Program for LGBTQ+ Youth
}

\author{
Alicia Lapointe \\ The University of Western Ontario \\ alapoint@uwo.ca

\section{Caely Dunlop} \\ The University of Western Ontario \\ cdunlo9@uwo.ca \\ Claire Crooks \\ The University of Western Ontario \\ ccrooks@uwo.ca
}

\begin{abstract}
This study evaluated the feasibility and fit of a mental health promotion and violence prevention program adapted for LGBTQ+ youth (ages 14-18). The pilot program included 16 30-minute sessions and was implemented in 8 gender and sexuality alliances (GSAs) and one community youth group setting. Extensive feedback was collected from 11 facilitators via session tracking sheets, ongoing email communication, an implementation survey, and a focus group; and from 7 youth who participated in a variety of feedback activities during a 2-day post-program workshop. Results indicated a strong interest in formalized programming, challenges related to its delivery in GSAs, and significant issues with its content. Facilitators and youth advocated for the program to be more affirmative, include youth-centered notions of identities and expressions, be trauma-informed, include a wider range of relationships, and adopt a youth-led approach.
\end{abstract}

Key words: adolescence, education, LGBTQ, positive youth development, program evaluation, qualitative methods

Lesbian, gay, bisexual, trans, and queer/questioning (LGBTQ+) youth commonly experience discrimination, harassment, and victimization in American and Canadian schools (Grace \& Wells,

(cc) EY New articles in this journal are licensed under a Creative Commons Attribution 4.0 License. This journal is published by the University Library System, University of Pittsburgh and is cosponsored by the University of Pittsburgh Press. The Journal of Youth Development is the official peer-reviewed publication of the National Association of Extension 4-H Agents and the National AfterSchool Association. 
Adapting a Mental Health Program for LGBTQ+ Youth

2015; Kosciw, Greytak, Giga, Villenas, \& Danischewski, 2016; Taylor et al., 2011), which elevates their risk for poor mental health (Meyer, 2003; Hall, 2017). A growing body of literature suggests that schools are well positioned to combat disparities in mental health among LGBTQ+ youth by providing comprehensive mental health promotion programming (Austin \& Craig, 2015a/b; Craig, 2013; Craig, Austin, \& McInroy, 2013; Heck, 2015). Gender and Sexuality Alliances (GSA ${ }^{1}$ ) are particularly relevant venues within schools to deliver mental health and violence prevention programming to LGBTQ+ youth (Heck, 2015; Lapointe \& Crooks, 2018. Although the supportive nature of these clubs has been well documented (Griffin, Lee, Waugh, \& Beyer, 2004; Miceli, 2005), Poteat, Heck, Yoshikawa, and Calzo (2017) contend that the benefits of GSAs may be strengthened with structured programming (e.g., guided questions) that prompts youth to explore, discuss, and cope with LGBTQ-based victimization in healthy ways.

GSAs are clubs where LGBTQ+ youth may build supportive networks and significant connections with their peers, receive and provide education about sexual and gender diversity (among other things, e.g., racism), and advocate for change at school and beyond (Griffin et. al., 2004; Mayo, 2017; Mayo, 2013, 2015; Miceli, 2005). GSAs positively impact school climate (Kosciw et al., 2016; Taylor et al., 2011), with LGBTQ+ students feeling safer and experiencing fewer instances of bullying and discrimination (Heck, Flentje, \& Cochran, 2011; Ioverno, Belser, Baiocco, Grossman, \& Russell, 2016; Kitchen \& Bellini, 2013; Kosciw et al., 2016; Marx \& Kettrey, 2016; Saewyc, Konishi, Rose, \& Homma, 2014). LGBTQ+ youth who attend schools with GSAs are at a lower risk for negative health behaviours, including alcohol and substance use, (Heck et al., 2014; Poteat, Sinclair, DiGiovanni, Koenig, \& Russell, 2013) and report increased psychological well-being and psychosocial functioning (Heck et al., 2011, 2014; Ioverno et al., 2016; Poteat et al., 2013; Saewyc et al., 2014; Toomey, Ryan, Diaz, \& Russell, 2013).

Although there are significant benefits to GSA formation, it is less clear if structured programming is desirable or beneficial to group members. As such, is essential to explore the extent to which GSAs are appropriate venues for more formalized programming, and determine what content, if any, is most appealing to youth (Heck, 2015). The purpose of this study was to evaluate the feasibility and fit of an evidence-informed mental health promotion and violence prevention program adapted for LGBTQ+ youth and delivered in GSAs and one community

\footnotetext{
${ }^{1}$ In recent years the acronym GSA has evolved from Gay-Straight Alliance to Gender and Sexuality Alliance to signify the group's commitment to affirming gender diversity.
} 


\section{Adapting a Mental Health Program for LGBTQ+ Youth}

youth group. As will be discussed in this paper, there are both benefits (i.e., structure, focus, curriculum, etc.) and challenges (i.e., drop-in club, limited time, fluctuating membership, etc.) associated with offering structured GSA programming.

\section{The Healthy Relationships Program (HRP) for LGBTQ+ Youth}

The HRP for LGBTQ+ Youth aims to promote mental wellness and positive relationship development among queer, trans, and gender diverse youth. The program includes 16, 30minute sessions and was adapted from The Healthy Relationships Plus Program (HRPP), an evidence-informed, small groups, universal prevention program for adolescents ages 14-18 designed to promote positive mental health and well-being, and prevent health risk behaviours. The adaptation for this pilot program was undertaken by an American researcher with expertise in the areas of queer dating relationships and interpersonal violence. Changes included: (a) exploring LGBTQ+ terminology; (b) identifying LGBTQ+ stressors; (c) incorporating relevant role play scenarios; and (d) discussing same-gender dating violence. The researcher, who is no longer involved with the program, prioritized these modifications because youth whom he worked with responded positively to similar material. Since his academic focus is on samegender intimate partner violence, he also included an abundance of content on this topic.

The purpose of this paper is to describe youth and facilitators' experiences with and perspectives on the pilot version of HRP for LGBTQ+ Youth. This paper critically analyzes the program's feasibility and fit within GSA contexts, and identifies program recommendations based on facilitator and participant feedback. The research questions that guide this inquiry are:

1. In what ways did the GSA and community group work as settings for structured healthy relationships and mental health programming (i.e., feasibility)?

2. In what ways did the adapted program meet (or not meet) the needs of LGBTQ+ youth (i.e., fit)?

\section{Methods}

\section{Participants}

Thirteen educators, professional support personnel (i.e., school nurse, guidance counsellor), and community partners facilitated the HRP for LGBTQ+ Youth at nine public high schools and one community organization. Eleven facilitators, who were assigned pseudonyms, across eight sites provided evaluation data. Two facilitators, who co-facilitated the program at one school, 
Adapting a Mental Health Program for LGBTQ+ Youth

did not offer feedback. Approximately 80 youth participated in the program in 2015-2016. The insights of seven youth, who participated in the program across three sites (i.e., two schools and one community agency), were also included. Youth were recommended by their facilitators to attend a paid 2-day workshop. Data were not collected on youth's intersecting identities.

\section{Procedure}

Representatives from the school district sent an email invitation to all GSA advisors on behalf of the research team, to invite them to pilot the HRP for LGBTQ+ Youth. A local social/support group for LGBTQ+ youth was also contacted. Individuals who were interested in facilitating the program were asked to attend a training session in November 2015. In addition to receiving LGBTQ-focused professional development and an orientation to the program, attendees were provided with an overview of the research components and asked to sign an implementation agreement. Facilitators who signed the agreement committed to facilitate all program sessions, complete session tracking sheets, provide ongoing feedback to the researchers, and attend a focus group or complete an online implementation survey. Between November 2015 and June 2016, the program was piloted in eight Ontario (Canada) public high school GSAs and one local social/support group for LGBTQ+ youth. Although facilitators agreed to facilitate each session, program implementation varied across school sites. One school conducted six sessions, and all others completed between 11 and 16 .

\section{Measures}

Qualitative data were collected through a variety of methods to capture the insights and experiences of facilitators and youth participants (Patton, 2002). Facilitators at each site completed a tracking sheet for each session. This one-page document asked facilitators to comment on the timing, successes, and challenges associated with program activities. At the end of the school year, eight facilitators participated in a 90-minute focus group where they were asked about the program's fit for their group, in/effective content, and recommendations. Facilitators who were unable to attend the focus group were asked to complete an online implementation survey with similar questions. Two of the four individuals who did not attend the focus group completed this survey. In addition to these formal feedback channels, facilitators provided ongoing informal feedback via emails and face-to-face meetings with the first author. 


\section{Adapting a Mental Health Program for LGBTQ+ Youth}

At a 2-day post-program workshop, seven youth participated in a series of feedback activities. During a 'Start/Stop/Continue' activity, youth were divided into three smaller groups and asked to brainstorm what the program should start, stop, and continue doing. Small groups of youth (with an adult facilitator) reviewed sessions from the HRP for LGBTQ+ Youth manual and were asked to provide feedback on the program's content (e.g., accuracy and relevance) and learning strategies, and to suggest areas for improvement. Youth were also asked to write/illustrate one wish they had for the program during the 'Wish for Program' activity. Lastly, youth had the opportunity to write or draw things that they wanted future facilitators to know about HRP for LGBTQ+ Youth participants.

\section{Data Analysis}

Throughout program implementation, the first author actively sought out "patterns across stories, experiences, and perspectives" (Patton, 2002, p. 6) and documented reoccurring insights with the use of analytic memos (Patton, 2002). To make sense of the texted-based data (i.e., facilitator focus group, session tracking sheets, emails, and activities from the 2-day workshop), content analysis-deciding "what things go together to form a pattern, what constitutes a theme, what to name it, and what meanings to extract" (Patton, 2002, p. 442)was employed. All data were read and reread by the first author, who looked for "reoccurring words or themes" (Patton, 2002, p. 453). Smaller units of information (e.g., curriculum, group structure, and time) were identified through re-examining the data. These units were then grouped together based on commonalities and labelled accordingly (e.g., feasibility issue). Key themes that were identified though his process included: Feasibility, Fit, and Recommendations.

\section{Results}

In this section, we discuss our findings across three main themes: feasibility, fit, and recommendations for future programming.

\section{Feasibility of Programming in GSA and Community Contexts}

Within the Feasibility theme, a number of subthemes spoke to the acceptability of delivering the program within GSAs and community contexts. Both areas of fit (e.g., structure) and challenges (e.g., time) were identified. 


\section{Curriculum}

Unlike the Live Out Loud organization's suggested GSA activities (Live Out Loud, 2018), the HRP for LGBTQ+ Youth provides guidance in the form of detailed curriculum to implement. Many facilitators welcomed the 'ready-to-go' curriculum that was easy-to-follow, and could provide a central focus for youth. In a facilitator focus group for example, Cooper expressed, "We had been struggling the previous year with our GSA for finding a focus . . . we were sort of a hangout group, but then there were kids who wanted more focus. So, this offered them that focus," and Jayden commented, "As teachers, you're busy, you already have your own lessons, and it's like, 'geez, I got to have another one.' So, it gave you a lot of stuff to pick and choose from."

Facilitators enjoyed having formal curriculum to draw from because it offered groups predetermined topics to discuss. Oakley contended that, "it was great having topics . . . they loved to have things to talk about," and Chester expressed, "It is a great go-to when you need a topic of discussion . . . a source of well laid out charts and exemplars." Having a program was particularly important for Ellis, a facilitator who was less familiar with advising a GSA, "With me not being a teacher and not being used to lesson plans...it was so nice to just open it up and 'okay, let's talk about this.' At least I could do something."

Although many facilitators were content with facilitating pre-packaged sessions in their GSA/community group, others disliked the prescriptive nature, such as Quinn, who found the program's structure to be "very rigid." Some youth were not enthusiastic about being told what to do in their club. When asked how the program was unfolding, Phoenix indicated, "[Youth] feel hijacked: they want the club to be about what THEY chose it to be about. They're not into the focus of the program." Similarly, Cooper related, "I think there were some kids who just didn't enjoy the structure as much."

In a response to the implementation survey, Ren communicated that they would not run the program consecutively in the future, "I tried to run the program every week instead of meetings. In the future, I would run it every other week and have meetings about school initiatives on the other weeks." To avoid disrupting the club's pre-established culture, Ren and Oakley implemented the HRP for LGBTQ+ Youth outside of regularly-scheduled meetings; youth were asked to sign up for the program, which was run in addition to the GSA. Although this strategy appeared promising, Oakley found that it was a lot of work to advise the GSA and facilitate the program in tandem. Despite being more taxing on advisors, offering the program outside of the GSA context may be more appealing to club members who simply want to 
Adapting a Mental Health Program for LGBTQ+ Youth

socialize or engage in informal conversations about school and home life (Lapointe, 2018). Since GSAs are for and by youth, it is of utmost importance to determine the youths' interest in participating in structured programming.

\section{Drop-In Nature}

The GSA is, by nature, a drop-in club; youth can come and go, and there are no obligations to attend meetings or arrive on time. This flexibility can undermine formal skill-based programming and low numbers can hinder group discussion, as Quinn disclosed, "[I] had to get a discussion going with only three students." In addition to low numbers, some facilitators found it difficult to deliver the program because youth entered the room at different times. Quinn commented, "Never knowing who was going to show up was always an issue, let alone the kids who came late and wondered what was going on."

\section{Limited Time}

Beyond encountering programmatic barriers as a result of low and fluctuating membership, facilitators found time to be another issue that impacted program delivery. HRP for LGBTQ+ Youth school-based facilitators communicated that it was difficult to run the program during school lunches because the time frame was too short and the session length was too long. Tatum shared, "There is never enough time for activities. The kids want to keep speaking and since we only have [about] 50 minutes at lunch time, there is just never enough time to fit everything in."

All facilitators felt obliged to facilitate the program's 'core info,' and as such, they used their best judgement to minimize non-essential content. In an email, Quinn commented, "I had to skip most of the preliminary stuff, opening [ice] breakers, sitting in the circle, some of the games, etc. If I tried to do all that, I was out of time before I got to the important stuff." Youth who attended the post-program 2-day workshop agreed, indicating that there were, "too many topics per session" and that there should be "more time [and] smaller session[s]."

During lunch periods there are often interruptions (e.g., announcements, other club/team meetings, etc.), which caused some students to miss sessions or arrive late, as Phoenix noted, "Time allotment is tricky . . . lots of school-related conflicts (half of my kids are in hospitality and are working over lunch and after school) . . . even finding a lunch where we can all meet is stupidly difficult (clubs, courses, other commitments, etc.)." The community group also 


\section{Adapting a Mental Health Program for LGBTQ+ Youth}

experienced group inconsistency, but they did not encounter programmatic interruptions to the same extent that school sites did. Because they had the ability to extend each session for up to two hours, the community group had ample time to deliver the program.

\section{Program Fit for LGBTQ+ Youth}

The following section outlines youth and facilitators' perspectives on the program's content and the extent to which it reflects the experiences and needs of LGBTQ+ youth. Subthemes included informational inaccuracies, lackluster LGBTQ+ focus and affirmation, and limited trauma awareness.

\section{Accuracy of Information}

Youth were particularly critical of the language and terminology used throughout the manual. When making a wish for the program, one youth yearned for the program to incorporate "Inclusive and accurate sexuality and gender terminology." Tatum reported, "My students were not fans of a lot of the terminology in the manual. They found that there were mistakes, mislabelling from the very first session and a lack of inclusivity regarding terms outside of the 'LGBT2Q' acronym." In some cases, youth were outraged by content they viewed as inappropriate (e.g., hetero/cisnormative, inaccurate terminology, etc.) and superficial compared to their postgay frame of reference (Lapointe, 2016a). In the Wish for Program activity, youth expressed that they believed that the program should, "Explain larger concepts like sexual orientation, romantic orientation, gender identity, gender expression" and "Get more in depth in the diversity of identities, experiences and people." The accuracy and quality of the program could have been greatly enhanced had LGBTQ+ youth been purposely included in the adaption process.

\section{$\angle G B T Q+$ Focus and Affirmation}

During the Start/Stop/Continue activity, youth communicated that the program needed to address its "crappy representation "and enhance its "queer representation." Facilitators agreed, and voiced that they observed youth critiquing the program developer's understanding of LGBTQ+ topics. Cooper noted that "[students] felt like this was a straight/cis program that had been retrofitted for the GSRM [community]." 
Adapting a Mental Health Program for LGBTQ+ Youth

Both youth and facilitators communicated that the program perpetuated problematic assumptions about LGBTQ+ people (e.g., all LGBTQ+ people are mere victims of homo/transphobia), and failed to acknowledge diversity within queer/trans communities. This criticism was articulated by an anonymous facilitator who completed the implementation survey:

I did not feel the program addressed the needs of our students as the individuals that they are - there was a sense of 'lumping' them into a $L G B T Q+$ category and that because of that they all have a common experience, or perspective - This is not the case.

Beyond identifying the superficial inclusion of LGBTQ+ content, both facilitators and youth voiced that LGBTQ+ affirmation did not permeate the program - a significant factor in combatting LGBTQ+ minority stress (Craig et al., 2013; Heck, 2015). During the facilitator focus group, Oakley explained, "there were a lot of times [the sessions] were just like, 'ouch, okay, bye,' like. it didn't feel affirming sometimes. . . . And I even felt that . . . right from the beginning." Instead of affirming LGBTQ+ identities/ways of being, the program tended to reiterate that queer, trans, and gender diverse people are simply victims of oppression. As such, the HRP for LGBTQ+ Youth failed to avow LGBTQ+ identities/ways of being, and empower youth to navigate sexual and gender-based stressors. The absence of positivity weighed heavily on youth who insisted that the program needed to emphasize pride rather than pain, as exemplified in one youth's wish for the program, "More affirmation and being proud for who you ARE."

Although, youth and facilitators called for more affirmative LGBTQ+ content, they did not want the program to eliminate content that explored LGBTQ+ challenges and stressors. They simply wanted the content to be more trauma-informed and strengths-focused.

\section{Trauma-Informed}

Although exploring and discussing LGBTQ+ marginalization can help youth cope with challenges that their straight and cisgender peers do not experience (Craig et al., 2013), some youth found the content to be triggering (i.e., they became upset, agitated, or angry). Chester asserted:

Most troubling is that many of the topics are of a very serious nature and although worthy of discussion can bring serious stress to students; as the teacher . . . I am deeply concerned about some of the material, but still recognize the value. 
Adapting a Mental Health Program for LGBTQ+ Youth

Youth in the Start/Stop/Continue activity advocated for the inclusion of "trigger warnings at [the] beginning of [particular] sessions" (e.g., mental health, microaggressions, etc.), because, as they stated in the Dear Facilitator activity, "People might get triggered." Some facilitators were keenly aware that youth could be activated, and some were concerned that they were not equipped to act. One youth wanted to remind facilitators that, for some, time and space is required to regain their composure after they are triggered, "I want you to remember to allow and remind students to leave whenever they feel uncomfortable."

Facilitators also expressed that sessions ended abruptly, leaving youth exposed. For example, during one activity entitled, Cutting Ties, where youth's hypothetical relationships were severed, there was no attempt to rebuild connections or discuss how one could move forward; instead, Phoenix jokingly remarked it was like, "...now that you've lost everyone in your whole entire life. See ya!" Likewise, Oakley commented that most sessions were overwhelmingly negative and required immediate intervention to minimize potential harms:

I had to strive to help it be affirming . . . session one, there was a part where it was like list all your stressors...And then it was like, ring goes the bell, and it was like, 'okay, bye everybody,' with all your stressors hanging on the page. . . . Even from the start I kind of walked away and felt, 'did we just do that? Did we just make them do that'?

The facilitators in the community organization made changes to the program to ensure that it was more emotionally safe and strengths-based. For example, during the 'Cutting Ties' activity they encouraged youth to think about how they could rebuild personal ties. Ruby insisted that sessions should provide opportunities ". . . to reconnect so that it's not like ... your life is terrible because you identify with this community." According to Cameron, "It's important to talk about this heavy stuff and this real stuff that people experience. But then there has to be . . . follow-up or making sure that people are leaving at a good place."

\section{Recommendations}

Facilitators and youth offered myriad recommendations throughout the pilot process. These suggestions included three subthemes: expanding the relationship content to include a broader range of relationships, keeping up with youth (i.e., promoting a more current understanding of sexual, gender, and romantic diversity), and emphasizing a youth-led approach. 


\section{Expanding Relationship Content}

Most facilitators believed that the program should focus on intrapersonal development and include more diverse relationship compositions. For example, Oakley insisted that "the different ways to date, or the different ways to be in a relationship . . . that was absolutely missing. " Many facilitators discussed how relationships were largely depicted as monogamous, romantic partnerships that subsequently developed into sexual relationships. They were particularly alarmed that asexuality, and platonic or aromantic relationships were not acknowledged as Cooper observed, "I think even in the scenarios it assumed that both parties....were wanting . . . a sexual monogamous relationship ... and then that's not true for every relationship."

Here, Cooper's reflections on the program's relationship content called for its heteronormative tendencies to be addressed. Rather than implying that all people are (or ought to be) monogamous or will eventually be sexually active, the program needed to reflect the reality that many queer and trans youth are polyamorous, aromantic, or asexual.

Besides neglecting to include a full range of sexual and relational diversity, the program deemphasized the importance of reflecting on and developing self, which is unfortunate because, according to Quinn, ". . . students are "very much" figuring out who they are." Phoenix explained further:

They also find the focus on relationships with significant others kind of limiting. Right now, I think most of them feel that they need to know how to get along with THEMSELVES more than another person and there doesn't seem to be enough on that aspect yet.

Phoenix believed that the program should stress the relationships LGBTQ+ youth have with themselves, including how they come to develop values and beliefs, "I was thinking rather than having it all being about dating the other, the relationship with the self . . . you know, how do you discover what your own values are?"

\section{'Keeping up' With $L G B T Q+$ Youth}

In the Start/Stop/Continue activity, youth were adamant that the program should "start educating the facilitators/teachers," and in the Dear Facilitator activity, youth wanted facilitators to understand that there are multiple sexualities and genders, including non-binary ones (e.g., bi/pansexuality, genderqueer, etc.). To boost facilitators' awareness, youth suggested that they 
Adapting a Mental Health Program for LGBTQ+ Youth

engage in self-directed research (see Lapointe, 2016b), rather than relying on LGBTQ+ youth to answer their questions:

I want you to keep in mind not everyone is on a binary, is sexual, only has one identity. There are many identities . . respect their identity. . . . Don't rely on $L G B T Q+$ folks to define and explain your questions. Do research first - hear the stories straight from $\angle G B T Q+$ people (i.e., YouTube, Tumblr, etc.).

I need you to know that not all of us are walking, talking $L G B T 2 Q+$ encyclopedias. If you don't know a term, research it instead of asking students.

Youth also stressed the importance of curbing gender-based assumptions and respecting people's identified pronouns, with one youth proclaiming that "Genitals do not equal gender." To "respect pronouns," youth stressed that inquiring about "pronouns [is] a must. "More specifically, one youth called for facilitators to open meetings with a pronoun check-in, "Pronouns are very significant to some people so please never assume someone's pronouns and always do the check-in!"

\section{Promoting a Youth-Led Approach}

The community-based co-facilitators met regularly to adapt the program because, as written, it underestimated the knowledge and experiences that youth brought to the group. Cameron explained:

... something that I found less effective was that most of these [sessions] . . . tell the students or teach the students these types of things. Whereas, [youth are] coming with a wealth of knowledge... we were adapting the sessions so that they were taking more of a lead, or contributing more of the information as opposed us to telling them something.

Cameron's insights emphasized a need for GSA programming to encourage student-driven conversation (Heck, 2015). In this way, youth can share and learn with and from each other, and spearhead discussions that are meaningful and relevant to their lives (Lapointe \& Crooks, 2018). 


\section{Discussion}

In this study we utilized extensive qualitative data from facilitators and youth who were involved with a mental health promotion and violence prevention pilot program for LGBTQ+ youth in order to assess its feasibility and fit within GSAs and community contexts. Overall, we identified five main lessons from our findings:

1. Program adaptation was undertaken without sufficient theoretical or research grounding and without input from key stakeholders, including LGBTQ+ youth themselves. Since the pilot program did not espouse or affirm queer and trans-informed understandings of sex, gender, and sexuality (e.g., infuse anti-cisnormative language), it largely failed to resonate with LGBTQ+ youth. Key topics and issues in the lives of LGBTQ+ youth, such as coming out (Craig, 2013), were also neglectfully absent in the pilot program. Further iterations of the HRP for LGBTQ+ Youth have rectified the issues identified in this paper by (a) consulting with educators and facilitators, and utilizing their experiences and insights to rewrite the program; (b) working with LGBTQ+ youth and privileging their voices in the program analysis and revision process; and (c) ensuring that queer (i.e., sexuality as non-binary, fluid, contextual) and trans (i.e., unconscious selfunderstandings of sex and conscious experiences with gender, Serano, 2007/2016) perspectives are foundational to the program (see Lapointe \& Crooks, 2018).

2. There is a clear need for and interest in LGBTQ+ specific programming in schools and community settings (see also Lapointe \& Crooks, 2018). As an increasing number of jurisdictions mandate the provision of GSAs in secondary and elementary schools, we anticipate that the interest in structured materials will grow. Research has found that ". . . many advisors become involved [in LGBTQ+ programming] with little knowledge of GSA activities and LGBT issues" (Valenti \& Campbell, 2009, p. 244) and do not have the expertise or time to develop their own programming. Formalized sessions, along with professional learning opportunities (e.g., summer institute) may assist educators in developing their understanding of LGBTQ+ issues and topics and building their facilitation skill set (Greytak, Kosciw, \& Boesen, 2013). Despite programmatic issues (e.g., accuracy, relevance, etc.), youth valued most topics and discussions, and responded positively to the opportunity to participate in structured GSA programming when appropriate modifications were made by facilitators as discussed throughout this paper. 


\section{Adapting a Mental Health Program for LGBTQ+ Youth}

3. Although there were significant challenges associated with implementing the program through GSAs because of their structure and mandate, these challenges are not insurmountable. The importance of accessible school-based programming is clear; moving forward we will continue to examine program fit and adaptability in the school setting. For example, some facilitators recommended alternating structured programming with unstructured weeks (see also Lapointe \& Crooks, 2018). In another school, the program was offered as an additional lunchtime extracurricular during nonGSA meeting days. The community setting had more flexibility in terms of timing but unlike school-based programs, youth groups may be inaccessible to those with transportation or employment conflicts (Craig et al., 2013).

4. Major revisions to content were required, and these needed to be undertaken in close partnership with youth (Edwards, Jones, Mitchell, \& Hagler, 2016). The content changes required were philosophical (i.e., emphasizing affirmation), generational (i.e., adopting terms consistent with youth's experiences), and psychological (i.e., developing traumainformed practice). Over time, we have come to understand gender, sexual, and romantic minority identities and expressions in a much broader way (i.e., postgay; Lapointe, 2016a), but the original pilot materials did not reflect this more nuanced understanding and sexual, gender, and romantic diversity.

5. This project highlighted the importance of undertaking evaluation when adapting an existing evidence-based program for a new setting and population. There was significant interest in participating in this pilot, but we intentionally chose to keep it small and local. Given the significant revisions required, we are grateful that we did not share the pilot version of the program widely. Besides overhauling the content, subsequent revisions have attempted to address contextual differences and time demands by streamlining the program (e.g., shorter sessions, less complicated activities) and making it more flexible (i.e., posing more open-ended questions; creating affirmative and skills-based standalone sessions; encouraging and privileging youth-generated knowledge, etc.).

\section{Limitations and Future Directions}

There are some inherent limitations in this study. Facilitators responded to a recruitment email to participate in the pilot; as such, they likely represented a non-representative sample of GSA advisors. In addition, this project was carried out in a very specific Canadian context where there are support and legislated protections for queer and trans youth (i.e., anti-discrimination 
Adapting a Mental Health Program for LGBTQ+ Youth

national, provincial, and educational policies). This programming might look different and require alternate emotional safeguards within contexts where these protections are not embedded.

The main purpose of collecting data reported in this study was to inform the next steps of our program. We have shared the triumphs and challenges associated with this pilot in the hopes that it will assist others undertaking similar work. The recommendations outlined in this paper were integrated into a revised version of the program, which was piloted in nine school sites and one community youth group the following year. In addition to collecting similar facilitator data, we conducted focus groups with youth, and their insights, once again, shaped further revisions of the program (i.e., enhanced harm reduction content, expanded reflections on individual mental health; extended material on helping oneself and others). The revised program was overwhelmingly positively received by youth (Lapointe \& Crooks, 2018). With an increase in relevancy for LGBTQ+ youth, we hope to assess the impact of the program on promoting positive mental health and decreasing distress.

\section{References}

Austin, A., \& Craig, S. L. (2015a). Transgender affirmative cognitive behavioral therapy; Clinical considerations and applications. Professional Psychology: Research and Practice, 46(1), 21-29. doi:10.1037/a0038642

Austin, A., \& Craig, S. L. (2015b). Empirically supported interventions for sexual and gender minority youth. Journal of Evidence-Informed Social Work, 12(6), 567-578.

doi: $10.1080 / 15433714.2014 .884958$

Craig, S. L. (2013). Affirmative supportive safe and empowering talk (ASSET): Leveraging the strengths and resiliencies of sexual minority youth in school-based groups. Journal of LGBT Issues in Counseling, 74), 372-386. doi:10.1080/15538605.2013.839342

Craig, S. L., Austin, A., \& McInroy, L. B. (2013). School-based groups to support multiethnic sexual minority resiliency: Preliminary effectiveness. Child and Adolescent Social Work Journal 31(1), 87106. doi:10.1007/s10560-013-0311-7

Edwards, K. M., Jones, L. M., Mitchell, K. J., \& Hagler, M. A. (2016). Building on youth's strengths: A call to include adolescents in developing, implementing, and evaluating violence prevention programs. Psychology of Violence, 6(1), 15-21. doi:10.1037/vio0000022

Grace, A. P., \& Wells, K. (2015). Growing into resilience: Sexual and gender minority youth in Canada. Toronto, ON: University of Toronto Press. 
Adapting a Mental Health Program for LGBTQ+ Youth

Greytak, E. A., Kosciw, J. G., \& Boesen, M. J. (2013). Educating the educator: Creating supportive school personnel through professional development. Journal of School Violence, 12(1), 80-97. doi:10.1080/15388220.2012.731586

Griffin P., Lee C., Waugh, J., \& Beyer, C. (2004). Describing roles that gay-straight alliances play in schools: From individual support to social change. Journal of Gay \& Lesbian Issues in Education, 1(3), 7-22. doi:10.1300/J367v01n03_03

Hall, W. J. (2017). Psychosocial risk and protective factors for depression among lesbian, gay, bisexual, and queer youth: A systematic review. Journal of Homosexuality. doi:10.1080/00918369.2017.1317467

Heck, N. C. (2015). The potential to promote resilience: Piloting a minority stress-informed, GSA-based, mental health promotion program for LGBTQ youth. Psychology of Sexual Orientation and Gender Diversity, 2(3), 225-231. doi:10.1037/sgd0000110

Heck, N. C., Flentje, A., \& Cochran, B. N. (2011). Offsetting risks: High school gay-straight alliances and lesbian, gay, bisexual, and transgender (LGBT) youth. School Psychology Quarterly, 26(2), 161174. doi:10.1037/a0023226

Heck, N. C., Livingston, N. A., Flentje, A., Oost, K., Stewart, B. T., \& Cochran, B. N. (2014). Reducing risk for illicit drug use and prescription drug misuse: High school gay-straight alliances and lesbian, gay, bisexual, and transgender youth. Addictive Behaviors, 39(4), 824-828. doi:10.1016/j.addbeh.2014.01.007

Ioverno, S., Belser, A. B., Baiocco, R., Grossman, A. H., \& Russell, S. T. (2016). The protective role of gay-straight alliances for lesbian, gay, bisexual, and questioning students: A prospective analysis. Psychology of Sexual Orientation and Gender Diversity, 3(4), 397. doi:10.1037/sgd0000193

Kitchen, J., \& Bellini, C. (2013). Making schools safe and inclusive: Gay-straight alliances and school climate in Ontario. Canadian Journal of Educational Administration and Policy. 2013; 146, 1-37.

Kosciw, J. G., Greytak, E. A., Giga, N. M., Villenas, C., \& Danischewski, D. J. (2016). The 2015 National School Climate Survey: The experiences of lesbian, gay, bisexual, transgender, and queer youth in our nation's schools. New York, NY: GLSEN.

Lapointe, A. (2016a). Postgay. In E. Brockenbrough, J. Ingrey, W. Martino, \& N. M. Rodriguez (Eds.), Critical concepts in queer studies and education: An international guide for the twenty-first century (pp. 205-218). New York, NY: Palgrave Macmillian.

Lapointe, A. (2016b). Queering the social studies: Lessons to be learned from Canadian secondary school gay-straight alliances. Journal of Social Studies Research, 40(3), 205-215. doi:10.1016/j.jssr.2015.07.004

Lapointe, A. (2018). Gay-Straight Alliances and student activism in Ontario public secular and Catholic high schools. Retrieved from https://ir.lib.uwo.ca/etd/5248/ 
Adapting a Mental Health Program for LGBTQ+ Youth

Lapointe, A., \& Crooks, C. V. (2018). GSA members' experiences with a structured program to promote well-being. Journal of LGBT Youth. doi:10.1080/19361653.2018.1479672

Lee, C. (2002). The impact of belonging to a high school gay/straight alliance. The High School Journal, 85(3), 13-26. doi:10.1353/hsj.2002.0005

Live Out Loud (2018). Live Out Loud GSA road map. Retrieved from https://www.liveoutloud.info/liveout-loud-gsa-road-map/

Marx, R. A., \& Kettrey, H. H. (2016). Gay-straight alliances are associated with lower levels of schoolbased victimization of LGBTQ+ youth: A systematic review and meta-analysis. Journal of Youth and Adolescence, 45(7), 1269-1282. doi:10.1007/s10964-016-0501-7

Mayo, C. (2017). Gay-straight alliances and associations among youth in schools. New York, NY: Palgrave Macmillan.

Mayo, J. B. (2013). Critical pedagogy enacted in the gay-straight alliance: New possibilities for a third space in teacher development. Educational Researcher, 42(5), 266-275. doi:10.3102/0013189X13491977

Mayo, J. B. (2015). Youth work in Gay-Straight Alliances: Curriculum, pedagogy, and activist development. Child \& Youth Services, 36(1), 79-93. doi:10.1080/0145935X.2015.1015887

Meyer, I. H. (2003). Prejudice, social stress, and mental health in lesbian, gay, and bisexual populations: Conceptual issues and research evidence. Psychological Bulletin, 129(5), 674-697. doi:10.1037/0033-2909.129.5.674

Miceli, M. (2005). Standing out, standing together: The social and political impact of gay straight alliances. New York, NY: Taylor and Francis.

Patton, M. Q. (2002). Qualitative research \& evaluation methods ( $3^{\text {rd }}$ ed.). Thousand Oaks, CA: SAGE.

Poteat, V. P., Heck, N. C., Yoshikawa, H., \& Calzo, J. P. (2017). Gay-straight alliances as settings to discuss health topics: Individual and group factors associated with substance use, mental health, and sexual health discussions. Health Education Research, 32(3), 258-268. doi:10.1093/her/cyx044

Poteat, V. P., Sinclair, K. O., DiGiovanni, C. D., Koenig, B. W., \& Russell, S. T. (2013). Gay-straight alliances are associated with student health: A multischool comparison of LGBTQ and heterosexual youth. Journal of Research on Adolescence, 23(2), 319-330. doi:10.1111/j.15327795.2012.00832.x

Saewyc, E. M., Konishi, C., Rose, H. A., \& Homma, Y. (2014). School-based strategies to reduce suicidal ideation, suicide attempts, and discrimination among sexual minority and heterosexual adolescents in Western Canada. International Journal of Child, Youth \& Family Studies, 5(1), 89112.

Serano, J. (2007/2016). Whipping girl: A transsexual woman on sexism and the scapegoating of femininity (2 ${ }^{\text {nd }}$ ed. $)$. Berkley, CA: Seal Press. 
Journal of Youth Development | http://jyd.pitt.edu/ | Vol. 13 Issue 4 DOI 10.5195/jyd.2018.585 Adapting a Mental Health Program for LGBTQ+ Youth

Taylor, C., Peter, T., McMinn, T. L., Elliott, T., Beldom, S., Ferry, A., \& Schachter, K. (2011). Every class in every school: The first national climate survey on homophobia, biphobia, and transphobia in Canadian schools. Final report. Toronto, ON: Egale Canada Human Rights Trust. Retrieved from http://egale.ca/wpcontent/uploads/2011/05/EgaleFinalReport-web.pdf

Toomey, R. B., Ryan, C., Diaz, R. M., Card, N. A., \& Russell, S. T. (2013). Gender-nonconforming lesbian, gay, bisexual, and transgender youth: School victimization and young adult psychosocial adjustment. Psychology of Sexual Orientation and Gender Diversity, 1(S), 71-80. doi:10.1037/2329-0382.1.S.71

Valenti, M., \& Campbell, R. (2009). Working with youth on LGBT issues: Why gay-straight alliance advisors become involved, Journal of Community Psychology, 372), 228-248.

doi:10.1002/jcop.20290 